\title{
Regulation of Motoneuron Excitability via Motor Endplate Acetylcholine Receptor Activation
}

\author{
Stan T. Nakanishi, ${ }^{1}$ Timothy C. Cope, ${ }^{1}$ Mark M. Rich, ${ }^{1,2}$ Dario I. Carrasco, ${ }^{1}$ and Martin J. Pinter ${ }^{1}$ \\ Departments of ${ }^{1}$ Physiology and ${ }^{2}$ Neurology, Emory University School of Medicine, Atlanta, Georgia 30322
}

\begin{abstract}
Motoneuron populations possess a range of intrinsic excitability that plays an important role in establishing how motor units are recruited. The fact that this range collapses after axotomy and does not recover completely until after reinnervation occurs suggests that muscle innervation is needed to maintain or regulate adult motoneuron excitability, but the nature and identity of underlying mechanisms remain poorly understood. Here, we report the results of experiments in which we studied the effects on rat motoneuron excitability produced by manipulations of neuromuscular transmission and compared these with the effects of peripheral nerve axotomy. Inhibition of acetylcholine release from motor terminals for 5- $6 \mathrm{~d}$ with botulinum toxin produced relatively minor changes in motoneuron excitability compared with the effect of axotomy. In contrast, the blockade of acetylcholine receptors with $\alpha$-bungarotoxin over the same time interval produced changes in motoneuron excitability that were statistically equivalent to axotomy. Muscle fiber recordings showed that low levels of acetylcholine release persisted at motor terminals after botulinum toxin, but endplate currents were completely blocked for at least several hours after daily intramuscular injections of $\alpha$-bungarotoxin. We conclude that the complete but transient blockade of endplate currents underlies the robust axotomy-like effects of $\alpha$-bungarotoxin on motoneuron excitability, and the low level of acetylcholine release that remains after injections of botulinum toxin inhibits axotomy-like changes in motoneurons. The results suggest the existence of a retrograde signaling mechanism located at the motor endplate that enables expression of adult motoneuron excitability and depends on acetylcholine receptor activation for its normal operation.
\end{abstract}

Key words: acetylcholine; receptor; transmitter release; motoneuron; excitability; neuromuscular

\section{Introduction}

Much emphasis is placed on understanding the mechanisms underlying synaptic plasticity because of the widely held view that these mechanisms underlie learning and memory. Less is known about how neuronal excitability is regulated over time, although the underlying mechanisms ultimately dictate how neurons respond to changes in synaptic input levels (Marder et al., 1996; Zhang and Linden, 2003). Recent studies have provided evidence that activity in synaptic targets influences the intrinsic excitability of neurons during development (Nick and Ribera, 2000) and in culture (Li et al., 2004), possibly via retrograde signaling mechanisms. The same may also be true for adult spinal motoneurons in which some aspect of muscle innervation seems to play an important role in determining excitability (Mendell et al., 1994). The primary evidence for this is the observation that motoneuron electrical properties (both passive and active) change dramatically after the connection with muscle is interrupted by axotomy. Postaxotomy changes in motoneuron excitability persist for as long as motoneurons remain functionally disconnected from muscle (Foehring et al., 1986a; Pinter and Vanden Noven, 1989) and return to normal levels after muscle innervation is reestablished (Foehring et al., 1986a). These observa-

Received Dec. 13, 2004; revised Jan. 18, 2005; accepted Jan. 18, 2005

This work was supported by National Institutes of Health Grant NS24707.

Correspondence should be addressed to Dr. Martin J. Pinter, Department of Physiology, Emory University School

of Medicine, 615 Michael Street, Atlanta, GA 30322. E-mail: mpinter@physio.emory.edu.

DOI:10.1523/JNEUROSCI.5065-04.2005

Copyright $\odot 2005$ Society for Neuroscience $\quad$ 0270-6474/05/252226-07\$15.00/0 tions show that the recovery of normal motoneuron properties depends on muscle reinnervation and are consistent with the idea that the loss of functional innervation rather than axonal injury triggers postaxotomy changes in motoneuron electrical properties.

One common interpretation of these findings is that motoneurons depend on muscle for signals that modulate or enable the expression of motoneuron properties. Although this is certainly consistent with available evidence, some of the experimental manipulations used to study this issue leave open the possibility that the interruption of purely presynaptic mechanisms provokes the observed effects. An example is axotomy itself, in which premature return to the cell body of material normally transported along the axon in an anterograde direction could, in principle, trigger the effects of axotomy (Grafstein, 1983). Another example is intramuscularly injected botulinum toxin (botox), which can evoke axotomy-like changes in motoneurons after 2-3 weeks (Watson, 1969; Pinter et al., 1991) but exerts its primary action presynaptically, in which it inhibits acetylcholine (ACh) release (Molgo et al., 1990; Meunier et al., 2002).

The present study was designed to test whether the manipulation of postsynaptic components of muscle innervation influences motoneuron excitability. Specifically, we studied the effects of blocking motor endplate ACh receptors (AChRs) on motoneuron electrical properties and compared these with the effects of botulinum toxin and axotomy. The results show that the blockade of AChRs produces changes in motoneuron excitability that are quantitatively similar to axotomy in extent and in timing. 
Parts of this work have been published previously in abstract form (Nakanishi et al., 2004).

\section{Materials and Methods \\ Preliminary treatment}

Motoneuron data were collected from 20 adult female Wistar rats (250$350 \mathrm{~g}$; Charles River Laboratories, Wilmington, MA) that were randomly assigned to one of five treatment groups (four rats per group): control, axotomy, $\alpha$-bungarotoxin ( $\alpha$-btx), saline, and botox. With the exception of control animals, which remained untreated until the acute experiment, animals assigned to the axotomy, $\alpha$-btx, saline, and botox treatment groups were subjected to a chronic treatment period of 5-6 d preceding the acute experiment. Rats were initially anesthetized in a closed chamber with $5 \%$ isoflurane (Novaplus; Novation, North Chicago, IL) and maintained in an areflexive state with 3.5-4\% isoflurane. Under aseptic conditions, the medial gastrocnemius (MG) muscle or muscle nerve was exposed in the left hindlimb and treated as detailed below. After recovery from anesthesia, rats were housed individually and provided food and water ad libitum. Procedures were approved by the Emory University Institutional Animal Care and Use Committee.

Axotomy. The MG muscle nerve was isolated and crushed for $5 \mathrm{~s}$ using a pair of Dumont \# 5 forceps (Fine Science Tools, Foster City, CA) close to nerve entry into the muscle, with care to not damage muscle blood supply. The crushed MG nerve remained in continuity with the distal portion of the muscle nerve. The wound was closed using clips, and the acute experiment was conducted $5 \mathrm{~d}$ later.

$\alpha$-Bungarotoxin. On 4 consecutive days, $15 \mu \mathrm{g}$ of $\alpha$-btx dissolved in $140 \mu \mathrm{l}$ of PBS was injected at multiple sites directly into the MG muscle using a syringe with a 30 gauge needle. The hindlimb was then irrigated with sterile saline, and the wound was closed using clips. The animals received no injections on the fifth day, and motoneuron properties were studied in a terminal experiment the following day.

Saline. Rats assigned to the saline treatment group received the identical treatment schedule described above for $\alpha$-btx-treated rats, with the exception that the injection fluid consisted of PBS only.

Botulinum toxin. On 2 consecutive days, $5 \mathrm{U}$ (approximately five mouse $\mathrm{LD}_{50}$ units) of botox type A dissolved in $100 \mu \mathrm{l}$ of saline were injected using a syringe with a 30 gauge needle at multiple sites throughout the MG muscle. After each injection session, the hindlimb was irrigated with sterile saline and closed using wound clips. Motoneuron properties were studied $3 \mathrm{~d}$ after the final injection.

\section{Acute experiments}

Rats were anesthetized with pentobarbital (50 mg/kg, i.p.) with supplemental doses $\left(3-6 \mathrm{mg} \cdot \mathrm{kg}^{-1} \cdot \mathrm{h}^{-1}\right)$ administered as needed to maintain anesthesia throughout the acute experiment. A tracheotomy was performed to maintain a patent breathing pathway, a carotid catheter was inserted to the carotid artery to monitor blood pressure (maintained at $>70 \mathrm{mmHg}$ ), and a venous catheter was inserted into the internal jugular and used to administer dextrose Ringer's solution to maintain blood pressure. Core body temperature was monitored using a rectal probe and maintained at $37 \pm 1^{\circ} \mathrm{C}$ using a heated table and/or infrared lamp.

The left hindlimb was dissected to expose the triceps surae muscles and their muscle nerves. The common peroneal and sural nerve branches were cut distally and removed as far proximally as possible. The MG and lateral gastrocnemius-soleus (LGS) muscle tendons were dissected free from the calcaneous and separated. The MG and LGS muscle nerves were isolated from connective tissue and separated from the posterior tibial nerve. The dorsal laminas of vertebrae T10-S1 were exposed. After these procedures, each animal was secured in a frame that immobilized the vertebral column. A laminectomy was then performed on vertebrae T12L6, and the dorsal dura mater was removed. Exposed tissue around the spinal cord and hindlimb was covered with mineral oil.

Recording procedures. Bipolar stimulating/recording electrodes were placed on the MG and LGS muscle nerves for antidromic activation of motoneurons and for recording nerve potentials. A bipolar recording electrode was placed on the L5 or L6 dorsal root for recording nerve volleys. The dorsal root volley recording was used to set MG nerve stimulation intensity at $2.5 \times$ threshold for the most excitable fibers to ensure antidromic activation of all of the MG motoneurons and explore field potentials in the spinal cord. MG motoneurons were impaled using borosilicate glass microelectrodes (outer diameter, $1.2 \mathrm{~mm}$; resistance, 8-12 M $\Omega$; World Precision Instruments, Sarasota, FL) filled with $2 \mathrm{M}$ potassium acetate. After impalement of each MG motoneuron, the antidromic action potential was sampled first. Rheobase current was determined as the minimal current (50 ms pulse) injected intracellularly needed to evoke an action potential. Averages of action potentials evoked by intracellular stimulation were used to measure afterhyperpolarization (AHP) half-decay times by determining the time between the AHP peak amplitude and one-half of this value during the AHP decay. At the conclusion of each experiment, the conduction distance between the spinal cord and the MG nerve stimulation site was measured and used for determination of MG motor axon conduction velocity. Data were collected only from motoneurons with antidromic action potentials $>60 \mathrm{mV}$.

To avoid uncertainties about motoneuron identification because of possible stimulus spread among the nerve-stimulating electrodes, each motoneuron activated antidromically by stimulation of the MG nerve was also stimulated intracellularly with $0.5 \mathrm{~ms}$ suprathreshold current injections while being recorded from the MG muscle nerve. Averaged records of the electroneurogram (ENG) routinely showed an all-ornothing axonal action potential in the MG nerve linked to the intracellular stimulus, even in the proximal stump of previously axotomized MG nerves. Because of the relatively small distances between the recording electrodes and the muscle, the ENG recording electrodes also provided records of motor unit potentials, which were used to determine whether MG motoneurons could activate muscle fibers. In botox-treated animals, two pairs of EMG electrodes were also inserted into the MG muscle to obtain improved EMG records. All of the recordings were digitized and analyzed using custom software (LabWindows; National Instruments, Austin, TX).

Neuromuscular transmission. A separate series of animals was used to determine the status of neuromuscular transmission in MG muscles that received botox and $\alpha$-btx injections. At least two animals each were used to study the effects of toxin injections and to obtain control data from normal animals. The sequencing of intramuscular injections and the timing of terminal experiments were identical to that used for motoneuron property studies. AChR replacement allows possible recovery of functional connections between motoneurons and muscle fibers between daily $\alpha$-btx injections. To assess the extent of receptor replacement and consequent neurotransmission recovery, MG neuromuscular transmission was studied at three time points after $\alpha$-btx injections: 2 and $24 \mathrm{~h}$ after the second of two daily injections and $48 \mathrm{~h}$ after the last of four daily injections. The latter time point was identical to that used to study motoneuron properties (see above). Intramuscular injection procedures were identical to those described above.

For terminal experiments, rats were first killed using an overdose of pentobarbital injected intraperitoneally. MG muscles were removed and placed into a recording chamber perfused continuously with a Ringer's solution containing the following (in mmol/L): $118 \mathrm{NaCl}, 3.5 \mathrm{KCl}, 2$ $\mathrm{CaCl}_{2}, 0.7 \mathrm{MgSO}_{4}, 26.2 \mathrm{NaHCO}_{3}, 1.7 \mathrm{NaH}_{2} \mathrm{PO}_{4}$, and 5.5 glucose, $\mathrm{pH}$ 7.3-7.4 $\left(20-22^{\circ} \mathrm{C}\right.$; equilibrated with $95 \% \mathrm{O}_{2}$ and $\left.5 \% \mathrm{CO}_{2}\right)$. MG muscles were dissected further into strips by cutting along the longitudinal axis of the muscle. Muscle strips were stained with $10 \mu \mathrm{M}$ 4-(4-diethylaminostyryl)- $N$-methylpyridinium iodide (4-Di-2ASP) (Magrassi et al., 1987) and imaged with an upright epifluorescence microscope (Leica Microsystems, Bannockburn, IL). At this concentration, 4-Di-2ASP staining enabled the visualization of surface nerve terminals, as well as individual surface muscle fibers. All of the endplates at which data were collected were imaged and impaled within $100 \mu \mathrm{m}$ of the endplate. Two-electrode voltage clamp was used to record endplate currents (EPCs), as described previously (Rich et al., 2002). Quantal content was calculated directly by dividing the integrated area of averaged EPCs by the integrated area of averaged miniature EPCs (MEPCs). For determination of MEPC properties (frequency and amplitude), 1-2 min of MEPCs were collected.

Data analysis and statistics. Average values are presented \pm 1 SEM. Nested ANOVAs were used to test for treatment effects, and Tukey's honestly significant difference post hoc test was used to test the signifi- 


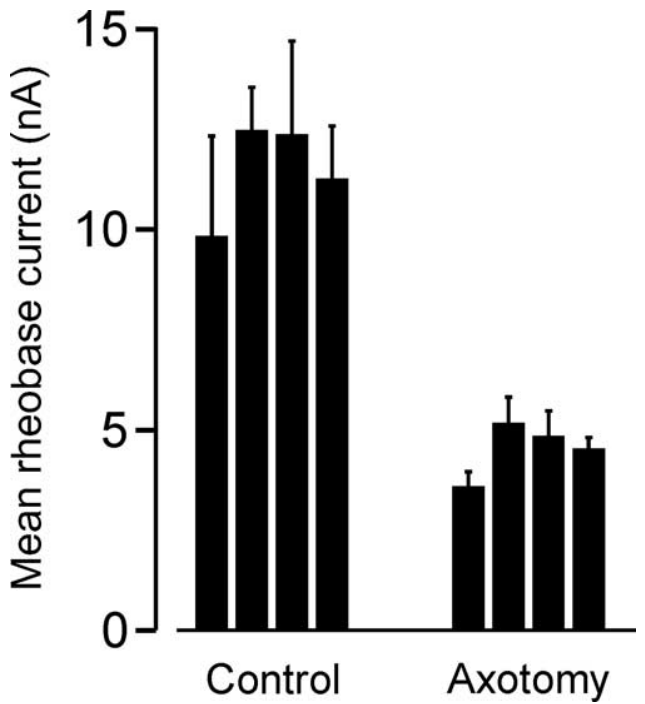

Figure 1. Axotomy increases motoneuron excitability. Data represent mean \pm SEM for MG motoneuron rheobase current measurements obtained from four normal, unoperated animals and from four normal animals in which the MG nerve had been crushed $5 \mathrm{~d}$ earlier. The crush site was located at the nerve entry into the MG muscle. Each mean value was derived from the data of at least eight motoneurons. Error bars represent SEM.

cance of comparisons of treatment effects using commercial software (SYSTAT; Systat Software, Point Richmond, CA).

\section{Results}

\section{Effects on motoneuron rheobase current}

Axotomy

Five days after crush of the MG nerve near its entry into the MG muscle, the mean rheobase current of MG motoneurons was significantly decreased compared with normal values (Fig. 1). The mean rheobase current for all of the experiments after axotomy was $4.5 \pm 0.34 \mathrm{nA}$, which was significantly lower than the mean rheobase current of control animals $(11.5 \pm 0.61 \mathrm{nA} ; p<$ 0.001). The decrease in rheobase current is similar to the effects of axotomy on motoneuron electrical properties reported previously in rats (Gardiner and Seburn, 1997) and in cats (Foehring et al., 1986b; Pinter and Vanden Noven, 1989). Neither AHP halfdecay nor MG motor axon conduction velocity showed significant changes $5 \mathrm{~d}$ after axotomy relative to control motoneurons $(p>0.05)$. Because changes in these properties are observed at longer postaxotomy intervals (Gardiner and Seburn, 1997), this indicates that these motoneuron properties change after axotomy with a longer time course than rheobase current. Differences in the rate at which electrical properties change after axotomy have also been observed in cat motoneurons, with rheobase current exhibiting the fastest change (single-exponential time constant, 2.3 d) (M. J. Pinter, unpublished observations).

\section{Botulinum toxin}

After intramuscular injections, botox is taken up into motor terminals, in which it acts to inhibit transmitter release (Meunier et al., 2002). Previous studies in cats have shown that botox induces an axotomy-like change in motoneuron properties after 2-3 weeks (Pinter et al., 1991). In the present study, in which motoneurons were sampled $5 \mathrm{~d}$ after botox injections, the effect on motoneuron rheobase was less. The mean rheobase current from four experiments performed after the $5 \mathrm{~d}$ treatment was $8.7 \pm$ $0.54 \mathrm{nA}$, which was significantly lower than control $(p<0.05)$ and significantly higher than axotomy $(p<0.001)$ but not significantly different from saline injections $(p=0.32)$ (Fig. 2).

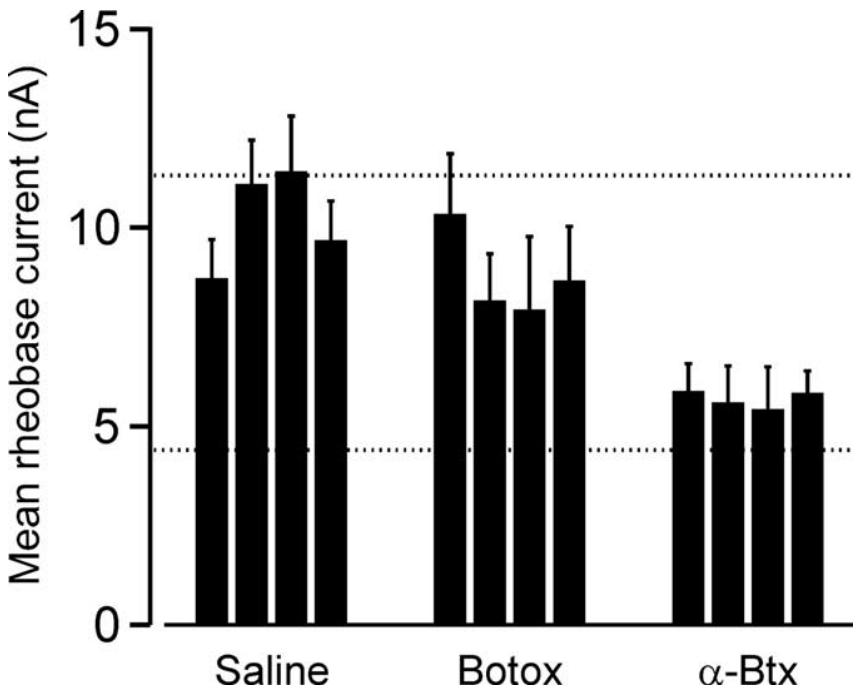

Figure 2. Blockade of AChRs increases motoneuron excitability to the same extent as axotomy. Each group of vertical bars show mean \pm SEM of MG motoneuron rheobase from individual experiments. Top and bottom dashed lines represent, respectively, the mean of mean values for MG motoneuron rheobase current from control animals and from animals with axotomized MG motoneurons. Botox was injected once daily into the MG muscle for 2 consecutive days, and motoneurons were studied after a 3 d delay. $\alpha$-Btx was injected once daily into the MG muscle for 4 consecutive days, and motoneurons were studied after an additional $2 \mathrm{~d}$ delay. Saline injections followed the same daily pattern used for $\alpha$-btx. Statistical analysis showed that the effects of $\alpha$-btx injections were indistinguishable from axotomy effects, whereas botox effects were indistinguishable from the effects of saline injections.

Neither AHP half-decay nor MG motor axon conduction velocity showed significant changes after botox injections relative to values from control or saline-injected animals $(p>0.05)$.

To determine whether motoneurons were capable of activating muscle fibers $5 \mathrm{~d}$ after botox treatment, average records of EMG potentials were obtained during intracellular stimulation of MG motoneurons. No motor unit EMG potentials were detected in $47 \mathrm{MG}$ motoneurons tested this way during four experiments. This result shows that $\mathrm{ACh}$ release from motor terminals at low motoneuron stimulation frequencies $(1 \mathrm{~Hz})$ was absent or insufficient to activate muscle fibers. However, during $50 \mathrm{~Hz}$ trains of suprathreshold stimulation pulses delivered directly to the muscle nerve, some twitching was observed in the MG muscle. This observation raises the possibility that, despite the apparent paralysis of motor units at low activation frequencies, some muscle fiber activity could have occurred in botox-treated MG muscles during the repetitive motoneuron activation that occurs during locomotion. Although we did not determine whether such activity occurred in this study, it is known that axotomized motoneurons are activated during locomotor step cycles (Gordon et al., 1980).

\section{Bungarotoxin}

$\alpha$-Btx is well known to selectively bind to and block nicotinic AChRs, such as those found at the motor endplate (Jones and Salpeter, 1983). In the present study, $\alpha$-btx was injected into the MG muscle for 4 consecutive days, followed by $1 \mathrm{~d}$ in which no injections were given. After this $5 \mathrm{~d}$ protocol, we observed that average MG motoneuron rheobase current was significantly decreased compared with both control motoneurons and motoneurons studied after saline injections (Fig. 2). In $\alpha$-btx-treated preparations, the mean $\mathrm{MG}$ motoneuron rheobase current was $5.7 \pm 0.11 \mathrm{nA}$, which was statistically indistinguishable from axotomized motoneurons ( $p=0.44$ ) and significantly lower than 
average motoneuron rheobase from control, saline-injected, and botulinum-treated animals $(p<0.01)$. Rheobase current did not differ significantly among MG motoneurons from control and saline-injected animals $(p=0.37)$. During terminal experiments, we also found that stimulation of most MG motoneurons (62 of 66) elicited a clear motor unit EMG signal from the MG muscle. This observation is consistent with the incomplete blockade of endplate ACh receptors and/or the occurrence of significant AChR replacement within $\sim 48 \mathrm{~h}$ after the final $\alpha$-btx injection. As with axotomized motoneurons, neither AHP half-decay nor MG motor axon conduction velocity showed significant changes after $\alpha$-btx relative to values from control or salineinjected animals $(p>0.05)$.

In summary, intramuscular injections of $\alpha$-btx resulted in a significantly reduced average MG motoneuron rheobase current that was indistinguishable from the effects of peripheral nerve crush (axotomy). In contrast, botox injections produced a milder effect that was indistinguishable from the effects of repeated intramuscular saline injections. Rheobase differences described above were not associated with differences in antidromic action potential amplitude among the various treatment groups $(p=$ 0.47). Because action potential amplitude and resting membrane potential are correlated in motoneurons (Pinter et al., 1983), this indicates that rheobase differences do not arise as a result of differences in resting membrane potential.

\section{Effects on neuromuscular transmission}

\section{Botulinum toxin}

Following the same treatment protocol used to study effects on motoneurons, we examined neuromuscular transmission in botox-treated muscles and compared the results with data from untreated normal animals. In all of the fibers examined, spontaneously occurring MEPCs were observed, but these occurred at a significantly lower frequency than in control fibers (Fig. $3 A$ ). However, a sufficient number of MEPCs could be obtained in all of the fibers to obtain average amplitudes, which were similar to normal (Fig. 3B). Nerve stimulation evoked EPCs in all of the fibers, but these were much reduced in amplitude compared with normal fibers and showed significant amplitude fluctuation. At low stimulation frequencies $(1 \mathrm{~Hz})$, mean quantal content was reduced $\sim 20$-fold relative to control (Fig. $3 C$ ). During highfrequency $(50 \mathrm{~Hz})$ repetitive stimulation, EPC amplitude facilitation appeared in botox-treated muscles, whereas in control muscle, EPC amplitude depression was observed (Fig. 3D). EPC amplitude facilitation likely reflects the reduction of quantal content observed after botox and probably underlies muscle twitching observed during high-frequency stimulation of the muscle nerve (see above). Thus, although neurotransmission was decreased in botox-treated muscle, it was not eliminated and continued at a low level. These findings are similar to those of previous studies that examined neuromuscular transmission at rat motor terminals $5 \mathrm{~d}$ after a single botox injection (Cull-Candy et al., 1976; Lundh et al., 1976, 1977).

\section{Bungarotoxin}

The effects of intramuscular $\alpha$-btx injections on neuromuscular transmission were studied at three time points. Several hours (2-4 h) after the second daily injection, we found a complete absence of all of the synaptic currents at endplates studied in 56 fibers from two animals. No EPCs were observed after electrical nerve stimulation, and no MEPCs could be detected. These observations demonstrate that the procedures used to deliver $\alpha$-btx were sufficient to completely block the occurrence of endplate
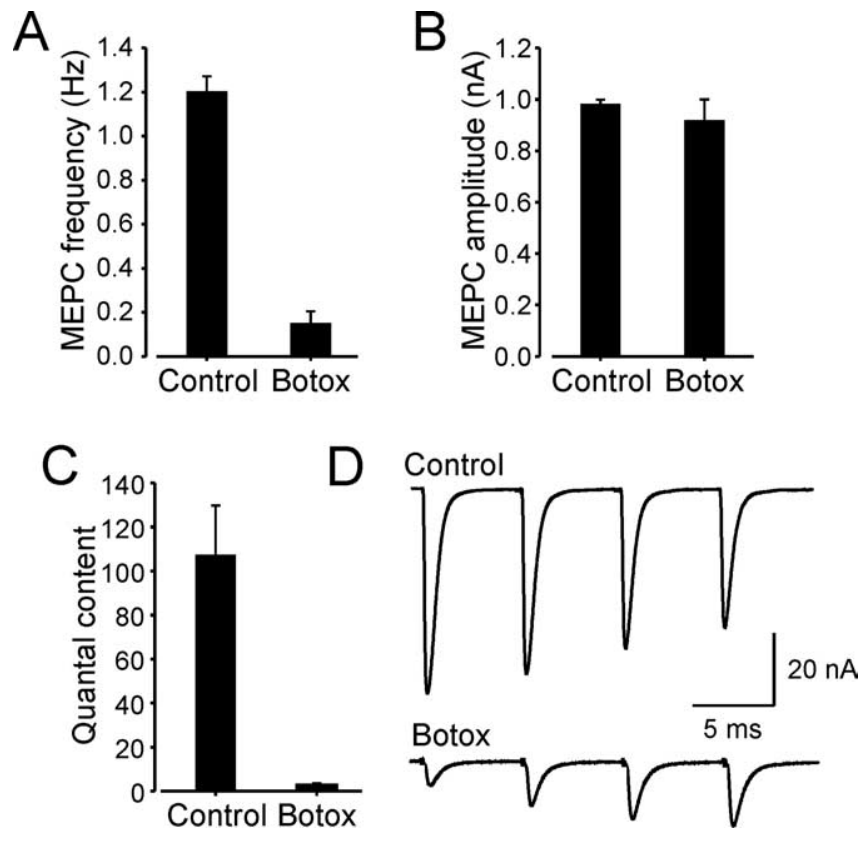

Figure 3. Effects of botulinum toxin on neuromuscular transmission at MG muscle NMJs. Effects were studied at the same delay as that used to study motoneuron properties after intramuscular injections of botox. $\boldsymbol{A}-\boldsymbol{C}$, Vertical bars show the mean \pm SEM of mean values obtained from individual control experiments $(n=3)$ and from botox-treated muscles $(n=3)$. Each experiment includes the data from at least eight muscle fibers. MEPC amplitude was unchanged relative to normal $(\boldsymbol{A})$, whereas MEPC spontaneous occurrence frequency was significantly depressed $(\boldsymbol{B})$. Quantal content (mean EPC integral/mean MEPC integral) was also significantly decreased after botox injections. D, At control NMJs, EPC amplitude typically showed depression during high-frequency nerve stimulation $(50 \mathrm{~Hz})$. Five days after botox treatment, the same stimulation produced facilitation of EPC amplitudes. Records were retouched to remove stimulus artifacts.

currents, at least during the hours immediately after each intramuscular injection.

By $24 \mathrm{~h}$ after the second daily injection, measurable MEPCs remained undetectable. Nerve-evoked EPCs, however, were observed at most endplates (35 of 39) studied in two animals but were significantly decreased in amplitude relative to normal (Fig. $4 A$ ). We also observed a significant increase in depression of EPC amplitude during low-frequency $(1 \mathrm{~Hz})$ stimulation (Fig. $4 B, C$ ). Despite this, no failures of EPC occurrence after nerve stimulation were observed at $\alpha$-btx-treated endplates, even after the lowest amplitudes were achieved (Fig. $4 B$ ). Although examined in only one $\alpha$-btx experiment, high-frequency depression also seemed to be increased. In eight fibers, the amplitude of the fourth EPC in a $50 \mathrm{~Hz}$ train was $37.6 \pm 4.4 \%(n=8)$ of the first EPC amplitude, whereas the same comparison yielded $80.3 \pm$ $1.5 \%$ in four control experiments, each of which included sampling from at least seven fibers. Previous studies have shown that the amount of ACh released at motor terminals increases significantly after several weeks of partial AChR blockade with $\alpha$-btx, and this is thought to be a compensatory response to decreased AChR density (Plomp et al., 1992, 1994). The increased EPC amplitude depression during low- and high-frequency activation might thus reflect an increased quantal content at motor terminals. This could not be confirmed directly in the present study, however, because the absence of detectable MEPCs prevented direct assessment of quantal content.

As noted above, motor unit EMG potentials were detected after intracellular stimulation of most motoneurons studied $48 \mathrm{~h}$ after the final (fourth daily) $\alpha$-btx injection. This demonstrates 

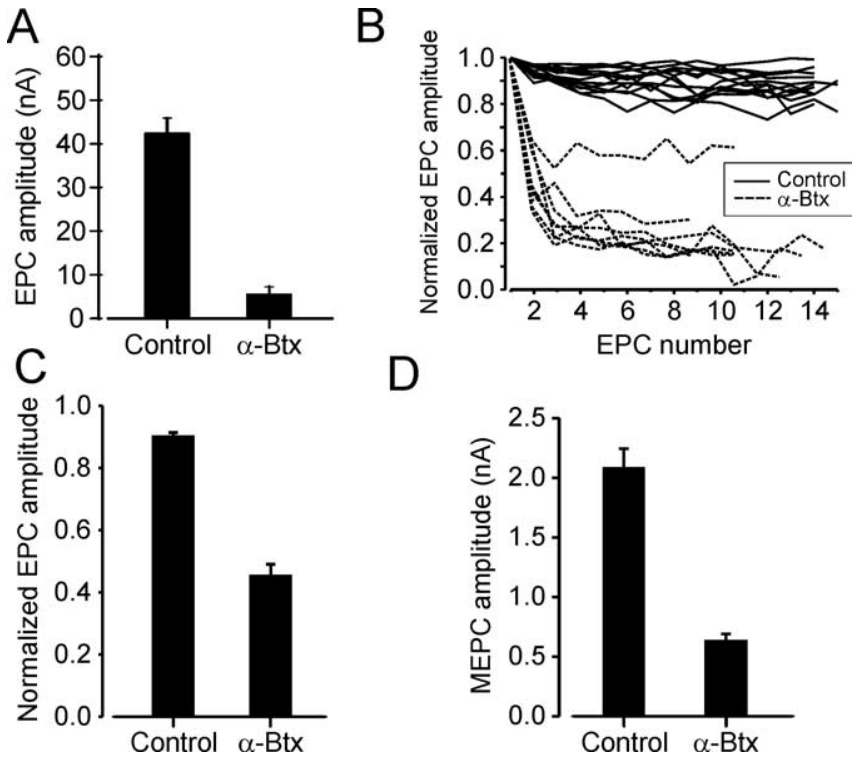

Figure 4. Effects of $\alpha$-btx on neuromuscular transmission at MG muscle NMJs. $\boldsymbol{A}$, Vertical bars show the mean \pm SEM of mean EPC amplitudes (holding potential, $-50 \mathrm{mV}$ ) obtained from individual control experiments $(n=3)$ and from MG muscle fibers studied $24 \mathrm{~h}$ after two daily $\alpha$-btx injections $(n=2)$. Each mean includes data from at least eight fibers. $\boldsymbol{B}$, Comparison of EPC amplitude depression at a stimulus rate of $1 / \mathrm{s}$ between EPCS obtained from one control experiment and from one experiment $24 \mathrm{~h}$ after two daily $\alpha$-btx injections. Each line represents data from one muscle fiber. EPC amplitudes are normalized to the amplitude of the first EPC in the sequence. $C$, Vertical bars show the mean \pm SEM of mean amplitudes of the fifth EPC normalized to the first EPC amplitude in sequences obtained at $1 / \mathrm{s}$ as in $\boldsymbol{B}$. Data obtained from MG muscles of two control animals and from MG muscles of two animals $24 \mathrm{~h}$ after two daily $\alpha$-btx injections. $D$, Vertical bars show the mean \pm SEM of mean MEPC amplitudes studied at a holding potential of $-120 \mathrm{mV}$ and obtained from a single control experiment and from MG muscles studied $48 \mathrm{~h}$ after four daily $\alpha$-btx injections $(n=2)$.

that EPCs were present at this time and possessed amplitudes sufficiently large to activate muscle fibers. Recordings obtained from MG muscle fibers at very hyperpolarized holding potentials showed that, although MEPCs could be detected at this time, average amplitude was significantly less than normal. For a holding potential of $-120 \mathrm{mV}$, average MEPC amplitude was $\sim 0.7$ $\mathrm{nA}$, whereas at the same holding potential, MEPC amplitude averaged $\sim 2.1 \mathrm{nA}$ at control neuromuscular junctions (NMJs) (Fig. $4 D$ ). Assuming a reversal potential of $\sim 0 \mathrm{mV}$ for MEPCs and no change in other factors that control MEPC amplitude, this suggests that AChR density was $\sim 30 \%$ normal by $48 \mathrm{~h}$ after the final $\alpha$-btx injection, when motoneuron properties were also examined. This is likely to represent the maximum extent of receptor-density recovery, because the smallest MEPCs probably escaped detection despite the hyperpolarized holding potential.

These data show that, after intramuscular injections of $\alpha$-btx, all of the endplate currents are blocked for a period, but by $24 \mathrm{~h}$ after the injection, some receptor replacement occurs to the extent that EPCs are again detectable. The treatment period preceding terminal experiments in which motoneuron properties were investigated is thus characterized by daily cycles of complete endplate current blockade followed by recovery of low levels of endplate current evoked by ACh release from motor terminals.

\section{Discussion}

The main finding of this study is that blockade of AChRs provoked a decrease in motoneuron rheobase current that was quantitatively as robust and as rapidly occurring as the rheobase decrease observed after axotomy (Fig. 2). Other studies have shown that nicotinic AChRs (which are blocked by $\alpha$-btx) are located in the muscle motor endplate and not on the presynaptic motor terminal (Jones and Salpeter, 1983). The present results thus demonstrate the existence of a mechanism located in muscle that depends on AChR activation for its operation and plays a significant role in determining mature motoneuron excitability via retrograde signaling. Apparently, the level of AChR blockade achieved by daily injections of $\alpha$-btx was sufficient to disrupt this mechanism, although the blockade itself was transient (Fig. 4).

\section{Muscle activity versus receptor activation}

A central question raised by our observations is whether activation of AChRs is sufficient to operate retrograde signaling or whether muscle fiber activity is also required. In this study, we used botox to inhibit ACh release from motor terminals. After $5 \mathrm{~d}$, we found that no motoneurons were capable of activating muscle fibers after intracellular stimulation and that no significant changes of motoneuron rheobase had occurred, at least in comparison with the effects of AChR blockade over the same time interval. Our in vitro studies indicate that ACh release was decreased $\sim 20$-fold after botox (Fig. 3 ).

One interpretation of this botox result is that the continued presence of ACh release and associated AChR activation, although very limited compared with normal, prevented changes in motoneuron rheobase despite the apparent muscle paralysis. We also observed, however, that small amounts of muscle fiber activity were provoked by repetitive nerve stimulation of botoxtreated muscles. This was most likely caused by facilitation of ACh release during repetitive activation, which we and others have observed at motor terminals after botox (Lundh et al., 1976, 1977). This raises the possibility that muscle fiber activity could have been produced in botox-treated MG muscles during episodes of synaptically driven repetitive motoneuron activity, such as occurs during locomotion. The possibility that such activity may have occurred prevents distinguishing confidently whether small amounts of ACh release or small amounts of muscle fiber activity inhibited rheobase changes after botox. Other studies have shown, however, that the blockade of motor axon action potentials in cats (Webb and Cope, 1992) and in rats (Gardiner and Seburn, 1997) for as long as 2 weeks does not produce axotomy-like changes in gastrocnemius motoneuron rheobase current. Complete loss of muscle activity is thus not sufficient to evoke axotomy-like changes in gastrocnemius motoneurons, and other factors must continue to maintain normal motoneuron properties. Each of these studies used tetrodotoxin (TTX) to block nerve action potentials, and, although TTX blocks action potential-evoked release of ACh at motor terminals, spontaneous quantal and nonquantal ACh release remain (Gundersen, 1990). AChR activation accomplished by this level of release seems sufficient to enable maintenance of normal motoneuron properties. Overall, these considerations favor the idea that AChR activation is sufficient to enable retrograde regulation of motoneuron excitability properties.

Other studies, however, have reported axotomy-like changes in adult motoneuron properties after the block of nerve action potentials with TTX (Czeh et al., 1978; Munson et al., 1985). In the most comprehensive of these studies, Czeh et al. (1978) used TTX to block nerve action potentials leading to the soleus muscle in cats and found axotomy-like changes in the AHP duration that could be prevented by electrical stimulation of the soleus nerve below the site of TTX application. These findings support the idea that at least some motoneuron properties might be regulated by muscle activity. It may, however, be significant that Czeh et al. 
(1978) studied motoneurons innervating the cat soleus muscle (which contains purely slow motor units), whereas the other studies in which TTX paralysis produced no changes studied motoneurons innervating the mixed-type gastrocnemius muscle in cat and rat, which feature a large proportion of fast motor units (Webb and Cope, 1992; Gardiner and Seburn, 1997). Previous studies have shown that motoneurons innervating slow-type units fire many more action potentials on a daily basis than do motoneurons that innervate fast-type motor units (Henning and Lomo, 1985). It has also been shown that the rate of spontaneous ACh release is lower at motor terminals of slow motoneurons than fast motoneurons (McArdle and Albuquerque, 1973). These observations indicate that nerve paralysis will eliminate proportionately more evoked ACh release among slow than among fast motoneurons and that less residual spontaneous release may remain. If AChR activation is crucial for regulating motoneuron excitability properties, then it may also be that this regulation is influenced not only by the presence but also by the amount of receptor activation. This could explain why TTX paralysis produces axotomy-like changes in some properties of slow motoneurons but not among fast motoneurons.

The idea that effective retrograde signaling may not simply depend on the presence of AChR activation, but also on the level of activation, can help explain an apparent inconsistency of botox effects. Previously, we showed that intramuscular injections of botox produced clear axotomy-like changes in cat MG motoneuron electrical properties (Pinter et al., 1991). In the present study, the effects of botox did not differ significantly from salineinjected preparations (Fig. 2). A potentially important factor to consider is that the present study examined motoneurons after $5 \mathrm{~d}$ of botox treatment, whereas Pinter et al. (1991) studied motoneurons after a 2-3 week postinjection delay. If retrograde signaling sufficient to enable expression of normal motoneuron properties depends on the level of AChR activation, then the difference between these studies might be explained by a progressive decline in ACh release from motor terminals after botox exposure. Some evidence for this possibility has been obtained by de Paiva et al. (1999), who studied vesicle recycling after botox exposure using FM1-43 [N-(3-triethylammoniumpropyl)-4-(4(dibutylamino)styryl) pyridinium dibromide] and showed an initial drop in recycling at the original motor terminals consistent with the known effects of botox to inhibit much (but not all) of the ACh release soon after the initial exposure. The data of de Paiva et al., however, also show a more progressive decline of vesicle recycling at the original motor terminals, which occurs over subsequent weeks, suggesting additional decreases in ACh release. ACh release may thus eventually reach a threshold below which AChR activation is insufficient to enable the maintenance of normal motoneuron properties. This could impose a delay in the appearance of axotomy-like changes and explain why changes in motoneuron properties are seen after 2-3 weeks (Pinter et al., 1991) but not after $5 \mathrm{~d}$ (present study).

A related issue concerns why the activation of newly replaced AChRs apparently failed to prevent rheobase changes or to promote recovery of rheobase current in MG motoneurons between $\alpha$-btx injections and for at least $48 \mathrm{~h}$ after the final $\alpha$-btx injection. One possibility is that the amount of receptor replacement that occurred within the $24 \mathrm{~h}$ period between injections did not allow generation of a signal sufficient to offset the effects of complete signal absence caused by the initial blockade. Another possibility is that AChR blockade also deactivates components of the retrograde signaling mechanism that are downstream from the AChR activation step. Activation of newly replaced AChRs may thus initially lack access to these downstream steps, and the daily elimination of replaced AChRs would presumably terminate any progress toward recovery. Another important consideration is that, even after axotomy, some time is required for the appearance of detectable rheobase current decreases. In rats, we estimate that 3-4 $\mathrm{d}$ are required. It may be that at least this amount of time is needed for recovery of normal motoneuron rheobase after retrograde signaling is reestablished. In this case, even the $48 \mathrm{~h}$ delay after the final $\alpha$-btx injection would have been insufficient to detect such recovery.

\section{Roles of retrograde signaling}

Retrograde signals derived from muscle are believed to mediate or influence motoneuron survival during development (Steljes et al., 1999; Oppenheim et al., 2001). It seems unlikely that any retrograde signaling based on AChR activation in muscle is needed for adult motoneuron survival because adult motoneurons survive peripheral axotomy for extended periods when denied reinnervation (Vanden Noven et al., 1993). On the other hand, the present results suggest that one role of this retrograde signaling may be to function as a kind of receipt for innervation that enables the expression and maintenance of adult motoneuron excitability properties. The adult range of motoneuron excitability properties plays a vital role in determining orderly recruitment of motor units, a factor underlying smooth force production by muscle (Gustafsson and Pinter, 1985; Cope and Pinter, 1995). The same signaling mechanism may also play an important role in driving events during reinnervation when reactivation of AChRs would presumably initiate the recovery of adult motoneuron properties. In conjunction with the elimination of any gap-junction coupling between motoneurons (Chang et al., 1999), this could help establish desynchronized motoneuron firing patterns (Binder and Powers, 2001) and drive synapse elimination, which otherwise would be inhibited by synchronous motoneuron firing (Busetto et al., 2000).

It also seems possible that motoneuron excitability and motor terminal synaptic properties are influenced in parallel by mechanisms driven by AChR activation. The increase of motoneuron excitability observed in this study (Fig. 2) and the increase of ACh release observed by others after AChR blockade (Plomp et al., 1992, 1994) may both be initiated by lost retrograde signaling and represent an integrated attempt by the motoneuron to maintain motor unit force output in the face of decreased AChR density at the endplate. Although retrograde signaling from muscle may be vital for determining motoneuron functional properties, it is also important to keep in mind the pivotal role of anterograde signaling from motoneurons for establishing mechanisms that likely enable retrograde signaling via AChR activation. For example, it is well established that factors released from motoneurons mediate or promote AChR clustering under motor terminals (McMahan et al., 1992; Burgess et al., 1999). Such evidence serves as a reminder that successful innervation likely involves many interdependent, bidirectional mechanisms, most of which remain only partially understood.

\section{References}

Binder MD, Powers RK (2001) Relationship between simulated common synaptic input and discharge synchrony in cat spinal motoneurons. J Neurophysiol 86:2266-2275.

Burgess RW, Nguyen QT, Son YJ, Lichtman JW, Sanes JR (1999) Alternatively spliced isoforms of nerve- and muscle-derived agrin: their roles at the neuromuscular junction. Neuron 23:33-44.

Busetto G, Buffelli M, Tognana E, Bellico F, Cangiano A (2000) Hebbian 
mechanisms revealed by electrical stimulation at developing rat neuromuscular junctions. J Neurosci 20:685-695.

Chang Q, Pereda A, Pinter MJ, Balice-Gordon RJ (1999) Nerve injury induces gap junctional coupling among axotomized adult motor neurons. J Neurosci 19:10813-10818.

Cope T, Pinter MJ (1995) The size principle: still working after all these years? News Physiol Sci 10:280-286.

Cull-Candy SG, Lundh H, Thesleff S (1976) Effects of botulinum toxin on neuromuscular transmission in the rat. J Physiol (Lond) 260:117-203.

Czeh G, Gallego R, Kudo N, Kuno M (1978) Evidence for the maintenance of motoneurone properties by muscle activity. J Physiol (Lond) 281:239-252.

de Paiva A, Meunier FA, Molgo J, Aoki KR, Dolly JO (1999) Functional repair of motor endplates after botulinum neurotoxin type A poisoning: biphasic switch of synaptic activity between nerve sprouts and their parent terminals. Proc Natl Acad Sci USA 96:3200-3205.

Foehring R, Sypert G, Munson J (1986a) Properties of self-reinnervated motor units of medial gastrocnemius of cat. I. Long-term reinnervation. J Neurophysiol 55:931-946.

Foehring RC, Sypert GW, Munson JB (1986b) Properties of selfreinnervated motor units of medial gastrocnemius of cat. II. Axotomized motoneurons and time course of recovery. J Neurophysiol 55:947-965.

Gardiner PF, Seburn KL (1997) The effects of tetrodotoxin-induced muscle paralysis on the physiological properties of muscle units and their innervations motoneurons in rat. J Physiol (Lond) 499:207-216.

Gordon T, Hoffer A, Jhamandas J, Stein R (1980) Long-term effects of axotomy on neural activity during cat locomotion. J Physiol (Lond) 303:243-263.

Grafstein B (1983) Chromatolysis reconsidered: a new view of the reaction of the nerve cell body to axon injury. In: Nerve, organ, and tissue regeneration: research perspectives (Seil FJ, ed), pp 37-50. New York: Academic.

Gundersen K (1990) Spontaneous activity at long-term silenced synapses in rat muscle. J Physiol (Lond) 430:399-418.

Gustafsson B, Pinter MJ (1985) On factors determining orderly recruitment of motor units: a role for intrinsic membrane properties. Trends Neurosci 8:431-433

Henning R, Lomo T (1985) Firing patterns of motor units in normal rats. Nature 314:164-166.

Jones SW, Salpeter MM (1983) Absence of [125I] $\alpha$-bungarotoxin binding to motor nerve terminals of frog, lizard and mouse muscle. J Neurosci 3:326-331.

Li C, Lu J, Wu C, Duan S, Poo M (2004) Bidirectional modification of presynaptic neuronal excitability accompanying spike timing-dependent synaptic plasticity. Neuron 41:257-268.

Lundh H, Cull-Candy SG, Leander S, Thesleff S (1976) Restoration of transmitter release in botulinum-poisoned skeletal muscle. Brain Res 110:194-198.

Lundh H, Leander S, Thesleff S (1977) Antagonism of the paralysis produced by botulinum toxin in the rat. J Neurol Sci 32:29-43.

Magrassi L, Purves D, Lichtman JW (1987) Fluorescent probes that stain living nerve terminals. J Neurosci 7:1207-1214.

Marder E, Abbott LF, Turrigiano GG, Liu Z, Golowasch J (1996) Memory from the dynamics of intrinsic membrane currents. Proc Natl Acad Sci USA 93:13481-13486.

McArdle JJ, Albuquerque EX (1973) A study of the reinnervation of fast and slow mammalian muscles. J Gen Physiol 61:1-23.
McMahan UJ, Horton SE, Werle MJ, Honig LS, Kroger S, Ruegg MA, Escher G (1992) Agrin isoforms and their role in synaptogenesis. Curr Opin Cell Biol 4:869-874.

Mendell LM, Collins WF, Munson JB (1994) Retrograde determination of motoneuron properties and their synaptic input. J Neurobiol 25:707-721.

Meunier FA, Schiavo G, Molgo J (2002) Botulinum neurotoxins: from paralysis to recovery of functional neuromuscular transmission. J Physiol (Paris) 96:105-113.

Molgo J, Comella JX, Angaut-Petit D, Pecot-Dechavassine M, Tabti N, Faille L, Mallart A, Thesleff S (1990) Presynaptic actions of botulinal neurotoxins at vertebrate neuromuscular junctions. J Physiol (Paris) 84:152-166.

Munson JB, Foehring RC, Sypert GW (1985) Nerve block with tetrodotoxin mimics axotomy of cat MG motoneurons. Soc Neurosci Abstr 11:335.3.

Nakanishi ST, Cope TC, Rich MM, Carrasco DI, Pinter MJ (2004) Muscle contraction is not necessary for the maintenance of normal motoneuron electrical properties. Soc Neurosci Abstr 30:418.17.

Nick TA, Ribera AB (2000) Synaptic activity modulates presynaptic excitability. Nat Neurosci 3:142-149.

Oppenheim RW, Wiese S, Prevette D, Armanini M, Wang S, Houenou LJ, Holtmann B, Gotz R, Pennica D, Sendtner M (2001) Cardiotrophin-1, a muscle-derived cytokine, is required for the survival of subpopulations of developing motoneurons. J Neurosci 21:1283-1291.

Pinter MJ, Vanden Noven S (1989) Effects of preventing reinnervation on axotomized spinal motoneurons in the cat. I. Motoneuron electrical properties. J Neurophysiol 62:311-324.

Pinter MJ, Curtis R, Hosko M (1983) Voltage threshold and excitability among variously sized cat hindlimb motoneurons. J Neurophysiol 50:644-657.

Pinter MJ, Vanden Noven S, Muccio D, Wallace N (1991) Axotomy-like changes of cat motoneuron electrical properties elicited by botulinum toxin depend on complete elimination of neuromuscular transmission. J Neurosci 11:657-666.

Plomp JJ, van Kempen GT, Molenaar PC (1992) Adaptation of quantal content to decreased postsynaptic sensitivity at single endplates in alphabungarotoxin-treated rats. J Physiol (Lond) 458:487-499.

Plomp JJ, van Kempen GT, Molenaar PC (1994) The upregulation of acetylcholine release at endplates of alpha-bungarotoxin-treated rats: its dependency on calcium. J Physiol (Lond) 478:125-136.

Rich MM, Waldeck RF, Cork LC, Balice-Gordon RJ, Fyffe REW, Wang X, Cope TC, Pinter MJ (2002) Reduced endplate currents provoke motor unit dysfunction while axonal functional properties mature normally in canine motor neuron disease. J Neurophysiol 88:3293-3304.

Steljes TP, Kinoshita Y, Wheeler EF, Oppenheim RW, von Bartheld CS (1999) Neurotrophic factor regulation of developing avian oculomotor neurons: differential effects of BDNF and GDNF. J Neurobiol 41:295-315.

Vanden Noven SV, Wallace N, Muccio D, Turtz A, Pinter MJ (1993) Adult spinal motoneurons remain viable despite prolonged absence of functional synaptic contact with muscle. Exp Neurol 123:147-156.

Watson W (1969) The response of motor neurones to intramuscular injection of botulinum toxin. J Physiol (Lond) 202:611-630.

Webb CB, Cope TC (1992) Modulation of la EPSP amplitude: the effects of chronic synaptic inactivity. J Neurosci 21:338-344.

Zhang W, Linden DJ (2003) The other side of the engram: experience-driven changes in neuronal intrinsic excitability. Nat Rev Neurosci 4:885-900. 